\title{
Genotoxicity among Hairdressers and the Level of Commitment to Occupational Safety Measures at Beauty Salons, in Zagazig City,
} Egypt

\author{
Rehab A. M. Hammam ${ }^{1}$, Nanees S. E. Ghareeb' ${ }^{1}$, Manar H. M. Arafa ${ }^{2}$, Hebatallah H. M. Atteia ${ }^{3}$ \\ ${ }^{1}$ Department of Community, Environmental and Occupational Medicine, Faculty of Medicine, Zagazig \\ University, Zagazig, Egypt \\ ${ }^{2}$ Department of Forensic Medicine and Clinical Toxicology, Faculty of Medicine, Zagazig University, Zagazig, Egypt \\ ${ }^{3}$ Department of Biochemistry, Faculty of Pharmacy, Zagazig University, Zagazig, Egypt \\ Email: ${ }^{*}$ Rehabhammam@yahoo.com
}

Received 17 February 2014; revised 20 March 2014; accepted 10 April 2014

Copyright $@ 2014$ by authors and Scientific Research Publishing Inc.

This work is licensed under the Creative Commons Attribution International License (CC BY). http://creativecommons.org/licenses/by/4.0/

(c) (i)

\section{Abstract}

Hairdressers are chronically exposed to several occupational hazards during their work including potentially genotoxic chemicals. Hair dying, hair smoothening and straightening products are hazardous chemicals that affect human health and are frequently used in beauty salons. So, this study aimed to evaluate the genotoxic risk among the studied hairdressers, to estimate the level of p-phenylenediamine (p-PDA) in urine and to assess the degree of adherence of the studied hairdressers to occupational safety measures at work. A comparative cross sectional study was carried out on 40 hairdressers working in beauty salons in Zagazig city, Egypt and 40 administrative staff at faculty of medicine as a control group. The results of the study revealed a significant increase in mean concentration of urinary p-PDA as well as significant increase in DNA damage assessed by Comet assay in lymphocytes among studied hairdressers than among their controls. Also, there was a statistically significant decrease in adherence to most of the occupational safety precaution measures that should be followed by the studied hairdressers. The significant risk factors of high Comet total mean score among the studied hairdressers were occupational use of hair straightening $\geq 8$ times/week, use of hair dyes at work $\geq 15$ times/week, length of service $\geq 13$ years, negligence of wearing gloves during work, use of bleaching agents $\geq 12$ /week and negligence of hand wash after handling chemicals. So, it was concluded that the hairdressers are occupationally exposed to the risk of genotoxic hazards from chemicals frequently used in their work. The lack of commitment to occupational safety measures at beauty salons like wearing gloves during work and hand washing increases the risk of genotoxicity.

\footnotetext{
${ }^{*}$ Corresponding author.
}

How to cite this paper: Hammam, R.A.M., Ghareeb, N.S.E., Arafa, M.H.M. and Atteia, H.H.M. (2014) Genotoxicity among Hairdressers and the Level of Commitment to Occupational Safety Measures at Beauty Salons, in Zagazig City, Egypt. Occupational Diseases and Environmental Medicine, 2, 19-29. http://dx.doi.org/10.4236/odem.2014.22003 


\section{Keywords}

\section{Hairdressers, Comet Assay, P-Phenylenediamine, Occupational Safety}

\section{Introduction}

Hairdressers, barbers and beauticians represent an important occupational group. This group will grow through 2016, more rapidly than the average of all occupations [1].

The hairdressers in beauty salons are chronically exposed to chemical and mechanical hair treatments as hairdyes, bleaching agents, permanent waves solutions, hair conditioners, hair sprays and perfumes. These substances contain a large number of potentially harmful chemicals, including resorcinol, aromatic amines, volatile solvents, diaminotoluene, formaldehyde, ammonia, ethanol and thioglycolic acid [2]. Recently hair straightening and smoothening products have been widely used in many beauty salons. OSHA conducted extensive testing of these products in the fall of 2010. The agency found significant levels of formaldehyde in many popular products, despite being labelled "formaldehyde free" [3].

Different mutagenic and carcinogenic compounds have been historically found in many brands of hair dye products because they contain aromatic amines [4]. Formaldehyde is used in a wide variety of cosmetics, including hair-straighteners. The World Health Organization (WHO) and the International Agency for Research on Cancer (IARC) classify formaldehyde as a human carcinogen, particularly in the nasal cavities. Formaldehyde exposure is linked to leukaemia and lung cancer [3]. Also, methylene chloride is a possible carcinogen. A risk estimate made by the FDA in 1985 estimated that one out of every hundred hairdressers may develop cancer from continued use of methylene chloride-containing hairsprays [5].

Evidence of cancer among hairdressers was first reviewed by the International Agency for Research on Cancer which reported an increased risk of urinary bladder cancer, lung cancer, upper aero-digestive tract cancer, breast cancer and non-Hodgkin's lymphoma in these professionals [6]. Moreover, some studies showed an increased risk of cancer among hairdresser that was most prominent in groups with the longest duration on this job [2]. A cohort study of hairdressers followed for cancer showed high risk for certain categories of cancer, comprising non-melanoma lung, skin, cervical, ovarian and pancreatic cancers [7].

The single-cell gel electrophoresis (SCGE) or Comet assay was first described by Östling and Johanson in 1984 [8], as a simple and sensitive method for studying DNA damage and repair. Like, other genotoxicity tests, the Comet assay can't predict individual cancer risk but it is considered as a useful and still reliable tool to assess early genotoxic effects due to occupational or environmental exposure [9].

Improvement of the ventilation system in the hairdressing salons, wearing protective gloves, aprons and chemical splash goggles plus implementation of hygiene measures at workplace, all can alleviate exposure to potential carcinogens and may reduce the risk of genotoxicity among hairdressers [3] [5] [7].

An increased risk of cancer among hairdressers would cause an important public health concern given to the large number of people employed in this sector. Also, there are no published genotoxic data concerning hairdressers in Zagazig city. Therefore, the objectives of this study were to use the Comet assay to evaluate the genotoxic risk among hairdressers compared to a control group (not exposed to similar work conditions), to estimate the level of p-phenylenediamine (p-PDA) in urine and to assess the degree of adherence of the studied hairdressers to occupational safety measures at work.

\section{Subjects and Methods}

\subsection{Study Design and Setting}

A comparative cross sectional study was conducted in Zagazig city, Sharkia governorate on 40 hairdressers and 40 administrative staff at faculty of medicine as a control group. Informed written consents had been taken from all participants in the present study. Previously arranged semi structured interview was conducted with all studied participants in their workplace to fill a designed questionnaire in purpose of the study. Blood samples were collected by trained personnel from them in a private setting during the same day of the interview. The interview and sample collection were scheduled to be in the last day of the working week. This study was conducted from November $1^{\text {st }} 2013$ to January $31^{\text {st }} 2014$. 


\subsection{Study Sample and Procedure}

As per Zagazig association of hairdressers, the number of licensed Hairdressers beauty salons in Zagazig city, Sharkia Governorate was 22 salons. The total population of hairdressers at these places at the time of the study was 55 male and female workers. All of them were requested to participate in this study according to the following criteria: hairdressers for more than 2 years, non-smokers or alcoholic, not on current medications or contraceptive pills or exposed to radiodiagnosis in the past 3 months and never received radio or chemotherapy.

Forty five hairdressers matched the inclusion criteria 43 females and only 2 males. So, the 2 male hairdressers were excluded. Only 40 of the 43 female hairdressers accepted to participate. Forty controls from the administrative female staff at Faculty of Medicine matched the criteria and accepted to participate in this study as well.

\subsection{Ethical Issues}

Proposal acceptance was obtained from the Institutional Review Board (IRB) of the Faculty of Medicine; Zagazig University. Moreover, informed consent was obtained from all participants after explaining the aim of the study and confidentiality of the information was assured.

\subsection{Data Collection and Measures}

1) Questionnaire data:

A structured questionnaire was used, based on those of other relevant studies and also on instructions and guidelines formulated by institutions concerned with health and occupational safety of hairdressers [2] [3] [5] [10] [11]. The questionnaire was introduced to participants in Arabic language. A pilot study was conducted on about $10 \%$ of the sample size population to assess the intelligibility of the questions and to identify any logistic problem. The result of the pilot study showed no logistic problems so it was included in the main survey. Hairdressers and controls completed the same questionnaire at work place in a period of 30 minutes using a semistructured interview schedule.

The questionnaire composed of three main parts: 1 . Socio-demographic and occupational data as: age, education, residence, marital status, duration of work, working hours per day and the chemicals frequently used during the working week. 2. Professional practice data as: usage of personal protective equipment (PPE), water proof coverage of wounded skin before work, use of protective creams on exposed skin and occupational safety knowledge and training courses. 3. Check list regarding ventilation of work place and application of occupational safety measures as: presence of hoods at work place, existence of odours more than 10 minutes, discovery of strong odours away from the source, remaining of product odours in the morning in hair salons, availability of material safety data sheets for workers, provision of PPE, safe storage of chemical substances, waste disposal of these substances, eating and drinking at workplace and the use of neutral $\mathrm{pH}$ soap or cream barrier before eating and/or drinking.

\section{2) Sample collection:}

\section{A) Blood sampling}

Five ml of peripheral venous blood samples were taken from all participants including controls by specialized medical personnel under complete aseptic condition in sterile heparinized disposable syringes. The blood samples were kept on ice and transferred within 2 hours in a dark container to the laboratory for analyses. Lymphocytes were then isolated from blood samples according to Boyum, 1976 [12], on a Ficoll-based density gradient and immediately used for Comet test.

\section{B) Urine sampling}

All workers were asked to wash their hands carefully before providing urine samples to prevent external contamination with p-phenylenediamine (p-PDA). Urine samples were taken on the last day of a work week to overcome variation in workloads throughout the week. Urine samples were stored at $-20^{\circ} \mathrm{C}$ immediately after collection to measure excretion of aromatic diamines (p-PDA) as a major component of commercially available hair dyes and Henna by gas chromatography-mass spectrometry (GC-MS) according to the method of Skarping et al., (1990); Gube et al., (2011); and Schettgen et al., (2011) [13]-[15] using Gas Chromatography-Mass Spectrometry (GC/MS) model Clarus 600 (PerkinElmer Life and Analytical Sciences, USA).

3) Laboratory investigation:

The alkaline Comet assay (Single Cell Gel Electrophoresis):

Comet assay was carried out in Animal Venereology Research Institute (El-Haram, Giza, Egypt). Alkaline 
electrophoresis was performed according to Singh et al., (1988), [16], with minor modifications. Briefly, lymphocyte pellets were resuspended in $75 \mu \mathrm{L}$ of $0.5 \%$ low melting point agarose (LMPA) (Sigma-Aldrich, St. Louis, MO, USA) prepared in $\mathrm{Ca}^{2+}$-, $\mathrm{Mg}^{2+}$-free PBS (Sigma) at $37^{\circ} \mathrm{sl} \mathrm{C}$ and placed on microscope ide, which was already covered with a thin layer of $0.5 \%$ LMPA and 1\% normal melting agarose (NMA) (HiMedia). After cooling at $4^{\circ} \mathrm{C}$ for $5 \mathrm{~min}$ on a slide tray resting on ice packs to harden, slides were covered with a third layer of $80 \mu \mathrm{L}$ LMPA. After solidification on the slide tray for $5 \mathrm{~min}$, slides were dipped in a prechilled lysing solution containing [2.5 M NaCl, $100 \mathrm{mM}$ ethylene diamine tetra acetic acid (EDTA)-2Na and $10 \mathrm{~m}$ MTris-HCl, pH 10] with the addition of 1\% Triton X-100 and 10\% dimethyl sulfoxide, for $24 \mathrm{hrs}$. The slides were incubated for $1 \mathrm{hr}$ in alkaline buffer solution ( $300 \mathrm{mM} \mathrm{NaOH}$ and $1 \mathrm{mM}$ EDTA, $\mathrm{pH} 13.2$ ), prepared at time of use at $4^{\circ} \mathrm{C}$ to allow for unwinding of the DNA and the expression of alkali-labile damage.

\section{Electrophoresis and staining:}

Cells on the slides were submitted to electrophoresis for $30 \mathrm{~min}$ in a horizontal electrophoresis platform at 300 milliamperes and $24 \mathrm{~V}$ at $4^{\circ} \mathrm{C}$. After that, the slides were neutralized by immersion and washing three times with neutralization buffer $(0.4 \mathrm{M}$ Tris- $\mathrm{HCl}, \mathrm{pH} 7.5)$ for $5 \mathrm{~min}$ each at $4^{\circ} \mathrm{C}$ to remove alkalis and detergents. These procedures were performed in the dark to minimize extraneous sources of DNA damage. Slides were then stained with $80 \mu \mathrm{L}$ of $(2 \mu \mathrm{L} / \mathrm{mL})$ ethidium bromide for 5 min followed by washing with chilled distilled water to remove excess stain. Positive controls were incubated for 2 hours at $37^{\circ} \mathrm{C}$ with $10 \mathrm{ul}$ of hydrogen peroxide to evaluate test efficiency and electrophoresis conditions. Following staining; the intensity of the stain was related to DNA content.

\section{Image analysis \& DNA migration (comet) assessment:}

Slides were examined at $40 \times$ objective on an epifluorescence microscope equipped with a 515 - $560 \mathrm{~nm}$ excitation filter. Images of 100 randomly selected cells from each subject were analysed with an automatic digital analysis system, comet 5 image analysis software developed by Kinetic Imaging linked to a CCD camera (Ltd. Liverpool, UK) to determine the quantitative and qualitative extent of DNA damage in the cells by measuring the length of DNA migration and the percentage of migrated DNA. Tail length and tail moment (tail length $\times$ tail \% DNA/100) were calculated from this program. DNA damage was further quantified by visual classification of cells into categories of "comets" corresponding to the amount of DNA in the tail according to Anderson et al. (1994), [17], Comet tail lengths (comprising nuclear region and tail) for each cell were manually scored into five Comet Classes: Class 0 (undamaged, no tail), Class 1 (tail up to 1.5 times the diameter of the comet nucleus), Class 2 (tail 1.5 - 2.0 times the diameter of the comet nucleus), Class 3 (tail 2.0 - 2.5 times the diameter of the comet nucleus) and Class 4 (maximally damaged, tail 2.5 times the diameter of the comet nucleus). A final overall DNA damage rating for all 100 cells (Comet Score) was obtained by summation of the number of cells in each class, yielding a rating between 0 (completely undamaged) and 400 (maximum damaged) [18].

\subsection{Statistical Analysis}

The collected data were computerized and statistically analysed using SPSS version 19, [19]. Student's t-test; was used to compare between group means while comparison between categorical qualitative data was done using Chi-squared test. Yates correction was used where needed. Univariate analysis was carried out initially to identify risk factors in terms of unadjusted odds ratios (OR) with their $95 \%$ confidence intervals (CIs). Then, stepwise multiple logistic regression analysis was carried out subsequently to identify independent determinants whilst adjusting results by potential confounders. The significance level was considered at p-value $<0.05$.

\section{Results}

\section{1) Socio-Demographic and Occupational Data}

The results of the present study showed that there was no statistical significant difference between studied hairdressers and their controls regarding age, marital status, residence, education, length of service and personal use of hair dyes. However, there was a significant increase in the frequency of using personal hair dyes per year and working hours per week among hairdressers than their controls (Table 1).

\section{2) Professional Practice Data and Degree of Adherence to Safety Measures}

The most chemicals that were used by the studied hair dressers/weak were hair dyes, bleaching agents, hair spray and hair straightening and smoothening products with mean frequencies (15.3 \pm 4.2$),(12.5 \pm 3.2),(9.5 \pm$ $2.2)$ and $(8.5 \pm 2.3)$; respectively. Moreover, there was a high statistical significant decrease among studied 
Table 1. Socio-demographic and occupational characteristics of participants.

\begin{tabular}{|c|c|c|c|}
\hline Demographic \& Occupational variables & Hairdressers N (\%) & Control N (\%) & $\mathrm{p}$-value \\
\hline Age (years) & $(28.9 \pm 9.1)$ & $(31.2 \pm 8.3)$ & $>0.05$ \\
\hline \multicolumn{4}{|l|}{ Marital status } \\
\hline Married & $15(37.5 \%)$ & $18(45 \%)$ & $>0.05$ \\
\hline Single/divorced/widowed & $25(62.5 \%)$ & $22(55 \%)$ & $>0.05$ \\
\hline \multicolumn{4}{|l|}{ Residence } \\
\hline Urban & 37 (92.5\%) & 38 (95\%) & $>0.05$ \\
\hline Rural & $3(7.5 \%)$ & $2(5 \%)$ & \\
\hline \multicolumn{4}{|l|}{ Education } \\
\hline Illiterate and basic education & $5(12.5 \%)$ & $0(0 \%)$ & $>0.05$ \\
\hline Secondary and above education & $35(87.5 \%)$ & $40(100 \%)$ & $>0.05$ \\
\hline Length of service (years) & $(13.2 \pm 4.3)$ & $(15.4 \pm 5.2)$ & $>0.05$ \\
\hline Work hours/week & $(50.1 \pm 5.5)$ & $(30.4 \pm 4.2)$ & $<0.0001$ \\
\hline \multicolumn{4}{|l|}{ Personal use of hair dyes } \\
\hline -Yes & $10(25 \%)$ & $3(7.5 \%)$ & $>0.05$ \\
\hline -No & $30(75 \%)$ & 37 (92.5\%) & \\
\hline Use of personal hair dyes/year & $(8.4 \pm 2.3)$ & $(4.5 \pm 1.1)$ & $<0.001$ \\
\hline
\end{tabular}

hairdressers in following up the safety measures during work especially hand washing, wearing PPE, use of protective creams, avoiding eating and drinking at workplace, knowing ingredients of chemicals used, reading instructions and warnings, knowing hazards of chemicals used and attending occupational safety training courses (Table 2).

3) Check List Regarding Ventilation of Work Place and Application of Occupational Safety Measures as

Figure 1 revealed that there was a statistical high significant increase of odours in work place $>10$ minutes as well as presence of strong odours away from the source. The studied hairdressers also, revealed high statistical significant decrease in availability of material safety data sheet (MSDS) and, PPE in workplace. Moreover, there were high statistical significant decrease regarding proper disposal of chemical wastes and cleaning of chemical spills.

\section{4) Mean Concentrations of Urinary p-PDA and Comet Score}

Table 3 explained that mean concentrations of urinary p-PDA (a mutagenic component of permanent hair dyes), which was significantly higher among studied hairdressers than among their controls with mean concentrations (17.37 $\pm 1.35 \mathrm{ng} / \mathrm{ml}$ and $1.92 \pm 0.17 \mathrm{ng} / \mathrm{ml}$; respectively).

Figure 2 and Table 4 showed that DNA damage among the hairdressers was significantly higher than that among the control group; Comet score (161.15 \pm 45.84$)$ compared to (93.6 \pm 20.13$)$; respectively. Also, class 3 and 4 of the Comet assay were frequently observed among hairdressers than that among the control group while class 0 (cells with no DNA damage) was frequently observed among control group than that among hairdressers.

Univariate analysis in Table 5 showed that, occupational use of hair straightening $\geq 8$ times/week, negligence of hand wash after handling chemicals, length of service $\geq 13$ years, use of hair dyes at work $\geq 15$ times/week, negligence of wearing PPE at work place, negligence of wearing gloves during work, use of bleaching agent $\geq 12$ week, frequent use of personal hair dyes $\geq 8$ times/year and working hours per week $\geq 50$ hours are significant risk factors of high Comet total mean score among studied hairdressers. Stepwise logistic regression showed that occupational use of hair straightening $\geq 8$ times/week, use of hair dyes at work $\geq 15$ times/week, length of service $\geq 13$ years, negligence of wearing gloves during work, use of bleaching agent $\geq 12 /$ week and negligence of hand wash after handling chemicals were significant risk factors of high Comet total mean score among the same group. 


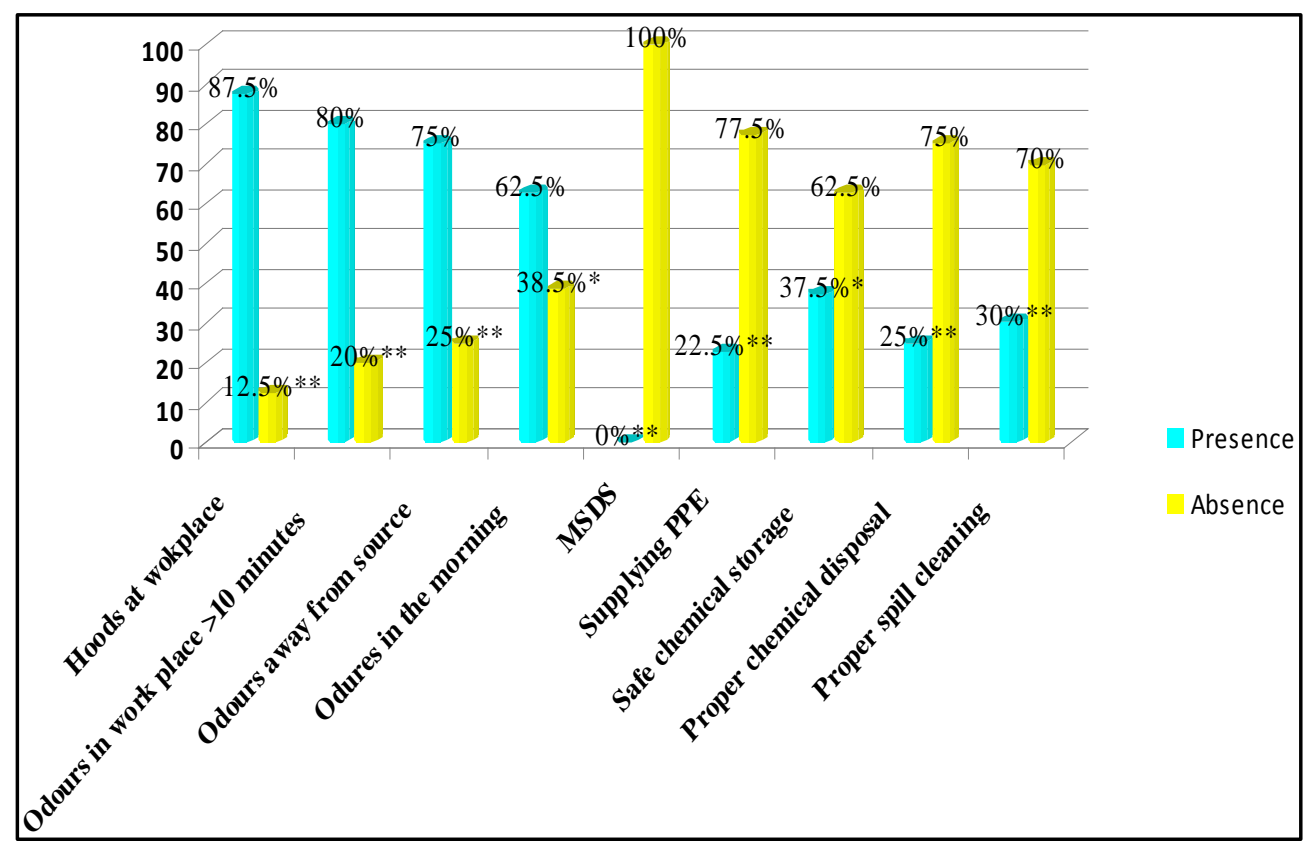

Figure 1. Ventilation in the work place and application of occupational safety measures. * Significant $<0.05 ;{ }^{* *}$ Highly significant $=0.000$.
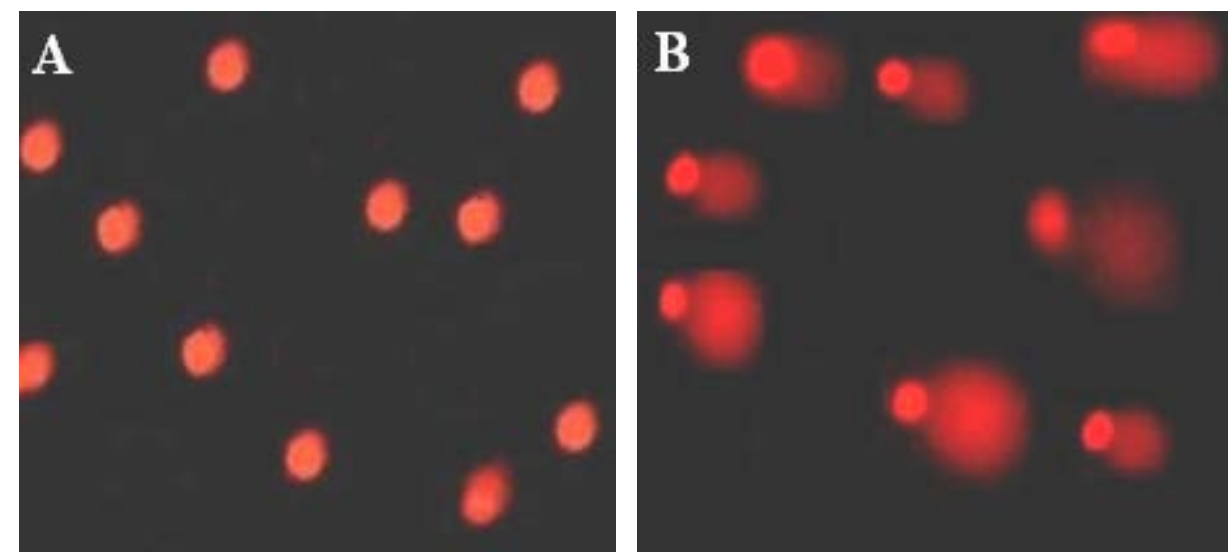

Figure 2. Photomicrographs of peripheral blood lymphocytes of the control group (A), showing fluorescent spheres without DNA damage (no tail) and the hairdresser group (B), showing a lot of fluorescent heads with tails indicating DNA damage (ethidium bromide stain).

Table 2. Occupational safety measures followed by studied hairdressers.

\begin{tabular}{cccc}
\hline Safety measures variables & Yes (\%) & No (\%) & p-value \\
\hline Wearing gloves during work & $18(45 \%)$ & $22(55 \%)$ & $>0.05$ \\
Hand washing after handling chemicals & $10(25 \%)$ & $30(75 \%)$ & 0.000 \\
Wearing personal protective equipment & $5(12.5 \%)$ & $35(87.5 \%)$ & 0.000 \\
Covering injured skin during work & $20(50 \%)$ & $20(50 \%)$ & $>0.05$ \\
Use of protective creams on exposed skin & $4(10 \%)$ & $36(90 \%)$ & 0.000 \\
Avoid eating and drinking at workplace & $0(0 \%)$ & $40(100 \%)$ & 0.000 \\
Use of neutral pH before eating or drinking & $0(0 \%)$ & $40(100 \%)$ & 0.000 \\
Knowing ingredients of chemicals used & $8(20 \%)$ & $32(80 \%)$ & 0.000 \\
Reading instructions and warnings & $6(15 \%)$ & $34(85 \%)$ & 0.000 \\
Knowing hazards of chemicals used & $6(15 \%)$ & $34(85 \%)$ & 0.000 \\
Occupational safety training courses & $5(12.5 \%)$ & $35(87.5 \%)$ & 0.000 \\
\hline
\end{tabular}


Table 3. Mean concentrations of urinary p-PDA in studied hairdressers and their controls.

\begin{tabular}{|c|c|c|c|c|c|c|c|}
\hline \multicolumn{4}{|c|}{ Variable } & \multicolumn{2}{|c|}{ Hairdressers } & Control & p-value \\
\hline \multicolumn{4}{|c|}{$\begin{array}{l}\text { Mean concentrations of urinary p-PDA } \\
\qquad(X \pm S D)(\mathrm{ng} / \mathrm{ml})\end{array}$} & \multicolumn{2}{|c|}{$17.37 \pm 1.35$} & $1.92 \pm 0.17$ & $<0.0001$ \\
\hline Comet classes & $\mathbf{0}$ & 1 & 2 & 3 & 4 & Total Comet score & p-value \\
\hline $\begin{array}{l}\text { Hairdressers } \\
\quad(X \pm S D)\end{array}$ & $36.3 \pm 9.2$ & $28.6 \pm 6.89$ & $19.2 \pm 5.41$ & $15.65 \pm 6.63$ & $9.65 \pm 2.23$ & $161.15 \pm 45.84$ & $<0,0001$ \\
\hline $\begin{array}{c}\text { Control } \\
(X \pm S D)\end{array}$ & $75.9 \pm 17.2$ & $7.95 \pm 1.79$ & $5.35 \pm 2.99$ & $3.25 \pm 1.25$ & $1.5 \pm 0.83$ & $93.6 \pm 20.13$ & \\
\hline
\end{tabular}

Table 5. Risk factors associated with high Comet scores (more than total mean Comet score): results of univariate and stepwise multiple logistic regression analysis.

\begin{tabular}{ccc}
\hline Risk factors of high Comet scores & Unadjusted OR (95\% CI) & Adjusted OR (95\% CI) \\
\hline Use of hair straightening/week (>8) & $9.8(2.5-13.2)^{*}$ & $7.2(2.8-13.6)^{*}$ \\
Use hair dyes/week (>15) & $6.7(1.6-5.3)^{*}$ & $4.5(2.4-8.6)^{*}$ \\
Length of service (>13) & $7.1(2.84-11.2)^{*}$ & $3.7(1.7-6.7)^{*}$ \\
Wearing gloves during work (No) & $6.1(1.3-12.2)^{*}$ & $2.6(1.6-7.2)^{*}$ \\
Use of bleaching agent/week (>12) & $5.3(1.2-16.2)^{*}$ & $2.1(1.8-4.2)^{*}$ \\
Hand washing after handling chemicals (No) & $7.7(1.9-18.9)^{*}$ & $1.8(1.2-4.3)^{*}$ \\
Frequent use of personal hair dyes/year(>8) & $5.1(2.3-16.6)^{*}$ & $2.9(0.82-6.4)$ \\
Wearing personal protective equipment (No) & $6.5(1.8-11.6)^{*}$ & $2.2(0.07-6.1)$ \\
Working hours per week (>50) & $4.2(2.1-6.3)^{*}$ & $1.1(0.6-5.4)$ \\
Use of hair spray/week ( $\geq 9)$ & $3.5(0.79-6.5)$ & - \\
Age (>29) & $3.5(0.73-7.9)$ & - \\
Covering injured skin during work (no) & $3.2(0.7-9.5)$ & - \\
Education (illiterate, read and write) & $2.0(0.23-10.8)$ & - \\
Personal use of hair dyes (yes) & $1.5(0.86-4.6)$ & - \\
Protective creams on exposed skin (no) & $0.8(0.07-9.2)$ & - \\
Residence (urban) & $0.38(0.01-6.2)$ & - \\
\hline
\end{tabular}

*Significant risk factors.

\section{Discussion}

Due to the high unemployment rate in Egypt 12.6\% [20], the small scale businesses like beauty industry are growing. The business of hair and beauty played a major role in generating employment chances. Forty female workers were employed in the 22 licensed Hairdressers beauty salons in Zagazig city, Sharkia governorate matched the inclusion criteria and accepted to participate in this study. Their mean age is $28.9 \pm 9.1$ and $87.5 \%$ of them are educated. The studied hairdressers spent a considerable duration in this occupation as their mean length of service in this field was $13.2 \pm 4.3$.

Hairdressers, are subjected to various occupational health risks (biological, physical, mechanical, ergonomically and chemical). There are a large number of chemical products in their work environments such as hair dyes, permanent wave solutions, shampoo, conditioner and various styling products [21]. The studied hairdressers re- 
ported the following chemicals as the most frequently used on weekly basis in their workstations (hair dyes, bleaching agents, hair sprays and hair straightening and smoothening products; respectively).

In Egypt hairdressing has a very long history. Among the Egyptians there were hairdressers as early as 5000 years BC and the art of dyeing hair with vegetable dyes was known already at that time [22]. However the hairdressing profession in Egypt is not subjected to government control or inspected by the occupational health authorities. So, there are no standards for work conditions or occupational safety measures to be followed by the hairdressers or the beauty salons owners. The results of this study reflect these facts as the studied hairdressers showed high statistically significant decrease in most of the studied occupational safety measures including wearing PPE, hand washing after handling chemicals, use of protective creams on exposed skin, not eating and drinking in workplace and use of neutral $\mathrm{pH}$ soap before eating or drinking. In the present study, there was a high statistical significant decrease in availability of PPE where, 77.5\% of the studied hairdressers reported that their employers don't supply them with all the required PPE. However, Lind et al., 2005, [22], proved that working with or without gloves during hair dying did not change the hair dye residues detected in hand rinse samples collected from hairdressers before the start of hair dying, after application of the dye and after cutting the newly dyed hair, this is because the glove use was often improper and was insufficient to prevent exposure.

The growing business of beauty salons needs to meet and maintain high standards of safety, health and hygiene so that no risk is present to customers and workers. Salon workers and clients both need to become aware and acquire knowledge on occupational injuries [21]. Regarding occupational safety knowledge among the studied hairdressers, the results of the present study showed that there were high statistical significant decrease in knowing ingredients of chemicals used at work, reading instructions and warning labels and knowing health hazards encountered by using these chemicals and/or even participating in occupational safety training courses. Union safe 2005 and OSHA 2010 [3] [11], stated that professionals in beauty salons can determine whether a product is a hazardous substance by reading its label and material safety data sheet (MSDS). In the present study all the studied workplaces didn't have any MSDS available for workers. Moreover $80 \%$ of the studied hairdressers reported that they don't read the labels on chemicals they use to be aware about their ingredients.

Although most of the studied beauty salons $87.5 \%$ had hoods, there was a high statistical significant increase of chemicals' odours in work place $>10$ minutes as well as presence of strong odours away from the source of triggering. This reflects the improper ventilation status of the studied workplaces which in consequences affects workers health through high exposures to inhalation of these chemicals.

Currently, p-PDA is present in more than 1000 hair dye formulations marketed all over the world. P-PDA is a suspected carcinogen that can induce DNA damage in lymphocytes [23]. The internal exposure to aromatic diamines in hairdressers using permanent hair dyes can be determined using biological monitoring. In the present study, the mean concentration of urinary p-PDA among studied hairdressers in the urine samples that had been taken from them in the last day of the working week was $17.37 \pm 1.35 \mathrm{ng} / \mathrm{ml}$ urine compared to $1.92 \pm 0.17$ $\mathrm{ng} / \mathrm{ml}$ urine among their controls. The mean concentration among controls is considered very low. The results of urine analyses among group of 18 professional hairdressers monitored by Hueber-Becker and colleagues 2007 [24], showed that the daily mean urinary excretion across all study subjects was $8.4 \pm 4.8 \mathrm{ng}$ P-PDAeq/mL urine or ug-PPDeq. The results variance between the present study and the study of Hueber-Becker and colleagues may be related to several factors like, the urine volume, time of taking urine specimen, the type of hair dyes used and/or the difference in frequency of using personal hair dyes. Also, Hueber-Becker and colleagues [24], concluded that occupational use of oxidative hair dyes among the hairdressers monitored in their study produces negligible local or systemic exposure to p-PDA. They refer this fact to the safety precautions for the handling of hair dyes that offer sufficient protection against local and systemic exposure. On contrast, to the present study where following occupational safety measures by the studied hairdressers were almost nil.

In addition to the effect of p-PDA, OSHA has reported that most of hair smoothening products that hairdressers use in beauty salons (even that labelled formaldehyde free) are containing considerable level of formaldehyde. Both the Environmental Protection Agency and the Federal Occupational Safety and Health Administration classify formaldehyde as a suspected human carcinogen because of links to nasal cancer and leukaemia, while NIOSH and the International Agency for Research on Cancer list it as a known human carcinogen [3].

The level of genetic damage in cells could be considered a good biomarker of effect, and in consequence an indicator of a future cancer risk. In recent years, single cell electrophoresis "the Comet assay" has been shown to be a very sensitive technique and a useful tool that is being widely used to detect genetic damage at individual cell level and in human bio monitoring [25]. The results of total comet score in the present study revealed high 
significant difference between the studied hairdressers and their controls in DNA damage (Comet score 161.15 $\pm 45.84)$ compared to (93.6 \pm 20.13$)$ respectively. These results matched that of Galiotte et al., 2008 [2], where there was a significant difference between Comet score of hairdressers and their controls with mean total Comet score $159.8 \pm 71.0$ and $125.4 \pm 64.1$; respectively. Also, Cho et al., 2003 [25], proved that acute exposure to hair dyes causes DNA damage in human lymphocytes by means of the Comet assay. On the other hand, Previous studies of occupational exposure to hair dyes reported no increases in the frequency of sister chromatid exchanges, or the levels of DNA damage measured with the Comet assay in professional hair colourists, which may indicate a higher risk associated to personal hair dye than from professional exposure [26]. Number of population studied, type of chemicals ingredients of hair dyes and level of adherence to safety precautions may affect all the previously mentioned results. So, complementary in vitro genotoxicity studies and further large scale studies are needed to get more clear information.

Stepwise logistic regression of risk factors associated with high Comet scores in the present study showed that occupational use of hair straightening $\geq 8$ times/week, use of hair dyes at work $\geq 15$ times/week, length of service $\geq 13$ years, negligence of wearing gloves during work, use of bleaching agent $\geq 12$ /week and negligence of hand wash after handling chemicals are significant risk factors of high Comet total mean score among the studied hairdressers. These results coincide with a review conducted by the IARC concluded that formaldehyde (main constituent of most hair straightening solutions) is carcinogenic in humans [27]. Also, Lee et al. (2001) [28], reported that there is a statistically significant dose dependent association between hair dying and risk of ovarian cancer. Moreover, Hueber-Becker et al., 2007 [24], proved that adherence to safety precautions for the handling of hair dyes offers sufficient protection against local and systemic exposure and thus against their occupational health hazards. Although bleaching agents appear to be safer than dyeing and the chemicals involved have not been associated with the long-term health effects of mutagenicity or carcinogenicity [5], there is increased risk of genotoxicity associated with increased exposure to bleaching agents in the present study. This may be related to a confounding factor of the association between using hair dyes and bleaching agents by clients at the same setting. So, genotoxicity is related to hair dyes not to the bleaching agent itself.

In the present study duration of occupational exposure was associated with increased risk of genotoxicity. On the other hand Galiotte et al., 2008 [2] found that the duration of occupational exposure did not correlate with Comet Score. Different quality of work conditions and poor adherence to occupational safety precautions of the studied hairdressers in the present study may explain this contrast.

\section{Conclusion and Recommendation}

Occupational exposure to hazardous chemicals in beauty salons carries the risk of genotoxicity to working hairdressers at these workplaces especially after exclusion of several confounding factors like smoking, alcohol intake and exposure to radiation. Commitment to occupational safety measures by hairdressers and their employers might alleviate this risk to a measurable extent. It is recommended to conduct large scale studies and to assess the levels of the hazardous chemicals in workplaces through environmental monitoring in further researches to get more information regarding this risk of genotoxicity.

\section{Competing Interests}

None has been declared. This research has been funded totally by the authors.

\section{Contributors}

Rehab A.M. Hammam designed the study and the questionnaire, determined the objectives wrote the manuscript and submitted the paper. Nanees Ghareeb conducted the practical phase, collected and analysed the data statistically shared in writing the methodology. Manar HM Arafa conducted the laboratory tests and shared in writing the methodology. Hebatallah HM Atteia conducted the laboratory tests and shared in writing the methodology. All authors revised the manuscript and have seen and approved the final version.

\section{Acknowledgements}

The authors would like to thank all participants of this study for their contribution in this work and their acceptance to give urine and blood samples for the laboratory tests. 


\section{References}

[1] Bureau of Labor Statistics (2009) Barbers, Cosmetologists, and Other Personal Appearance Workers. In: Occupational Outlook Handbook, 2008-2009 Edition. http://www.bls.gov/oco/ocos169.htm

[2] Galiotte, M.P., Kohler, P., Mussi, G. and Gatta, G.J.F. (2008) Assessment of Occupational Genotoxic Risk among Brazilian Hairdressers. Annals of Occupational Hygiene, 52, 645-651. http://dx.doi.org/10.1093/annhyg/men037

[3] OSHA (Occupational Safety and Health Administration) (2010) Keratin-Based "Hair Smoothing Products and the Presence of Formaldehyde”. Oregon, OSHA. A Division of the Oregon Department of Consumer and Business Services and CROET at Oregon Health \& Sciences University, Portland.

[4] Carlin, V., Fracalossi, A.C., Miranda, S.R., Noguti, J., Pereira da Silva, V.H., Oshima, C.T. and Ribeiro, D.A. (2013) Chromosome Breakage and Cellular Death Are Induced in Oral Epithelial Cells of Hairdressers: A Preliminary Study. Toxicology Mechanisms and Methods, 23, 108-112. http://dx.doi.org/10.3109/15376516.2012.721810

[5] Brown, N.J. (1987) Health Hazard Manual for Cosmetologists, Hairdressers, Beauticians and Barbers. Bureau of Occupational Health, New York State Department of Health, Albany.

[6] IARC (1993) Monographs of the Evaluation of Carcinogenic Risk to Human. Occupational Exposures of Hairdressers and Barbers and Personal Use of Hair Colourants; Some Hair Dyes, Cosmetic Colourants, Industrial Dyestuffs and Aromatic Amines. Vol. 57. World Health Organization, International Agency for Research on Cancer, Lyon.

[7] Takkouche, B., Regueira-Méndez, C. and Montes-Martínez, A. (2009) Risk of Cancer among Hairdressers and Related Workers: A Meta-Analysis. International Journal of Epidemiology, 38, 1512-1531. http://dx.doi.org/10.1093/ije/dyp283

[8] Östling, O. and Johanson, K.J. (1984) Microelectrophoretic Study of Radiation-Induced DNA Damages in Individual Mammalian Cells. Biochemical and Biophysical Research Communications, 123, 291-298. http://dx.doi.org/10.1016/0006-291X(84)90411-X

[9] Moller, P., Knudsen, L.E., Loft, S., et al. (2000) The Comet Assay as a Rapid Test in Biomonitoring Occupational Exposure to DNA-Damaging Agents and Effect of Confounding Factors. Cancer Epidemiology, Biomarkers \& Prevention, 9, 1005-1015.

[10] Work Cover New South Wales (2003) Health and Safety Guidelines for Hairdressers. Industry Reference Group. Consumer Service.

http://www.workcover.nsw.gov.au/formspublications/publications/Documents/hairdressers_health_safety_guide_0123. pdf

[11] Union Safe Labor Council of New South Wales (2005) Hairdressing, Nail and Beauty Safety. Hazardous Chemicals and Substances. http://unionsafe.org.au/hazards/hairdressing-nail-and-beauty-safety/

[12] Boyum, A. (1976) Isolation of Lymphocytes, Granulocytes and Macrophages. Scandinavian Journal of Immunology, 5, 9-15. http://dx.doi.org/10.1111/j.1365-3083.1976.tb03851.x

[13] Skarping, G., Brorson, T. and Sango, C. (1990) Biological Monitoring of Isocyanates and Related Amines. International Archives of Occupational and Environmental Health, 63, 83-88. http://dx.doi.org/10.1007/BF00379069

[14] Gube, M., Heinrich, K., Dewes, P., Brand, P., Kraus, T. and Schettgen, T. (2011) Internal Exposure of Hairdressers to Permanent Hair Dyes: A Biomonitoring Study Using Urinary Aromatic Diamines as Biomarkers of Exposure. International Archives of Occupational and Environmental Health, 84, 287-292. http://dx.doi.org/10.1007/s00420-010-0539-x

[15] Schettgen, T., Heinrich, K., Kraus, T. and Gube, M. (2011) Determination of 2,5-Toluylendiamine (2,5-TDA) and Aromatic Amines in Urine after Personal Application of Hair Dyes-Kinetics and Doses. Archives of Toxicology, 85, 127-133. http://dx.doi.org/10.1007/s00204-010-0563-3

[16] Singh, N.P., Mccoy, M.T., Tice, R.R., et al. (1988) A Simple Technique or Quantitation of Low Levels of DNA Damage in Individual Cell. Experimental Cell Research, 175, 184-191. http://dx.doi.org/10.1016/0014-4827(88)90265-0

[17] Anderson, D., Yu, T.W., Phillips, B.J. and Schmerzer, P. (1994) The Effect of Various Antioxidants and Other Modifying Agents on Oxygen-Radical-Generated DNA Damage in Human Lymphocytes in the Comet Assay. Mutation Research, 307, 291-298. http://dx.doi.org/10.1016/0014-4827(88)90265-0

[18] Collins, A.R. (2004) The Comet Assay for DNA Damage and Repair: Principles, Applications, and Limitations. Molecular Biotechnology, 26, 249-261. http://dx.doi.org/10.1385/MB:26:3:249

[19] IBM (2010) IBM SPSS Statistics 19 Core System Users' Guide. SPSS Inc., Chicago. http://www.IBM-SPSS-Statistics-User_s-Guide.pdf

[20] Central Agency for Public Mobilization and Statistics (CAPMAS) (2013) http://www.capmas.gov.eg/pdf/EgyptInFigure/EgyptinFigures/Tables/English/labor/labor\%20force/index.html

[21] Sedhain, G.P. and Adhikari, R. (2012) Occupational Health and Safety Awareness, Knowledge of the Risks and Practices of Risk Prevention of Hair and Beauty Salon Workers in Rural and Urban Areas of Western Nepal. Himalayan 
Journal of Sociology \& Anthropology, 5, 34-53.

[22] Lind, M.L., Boman, A., Sollenberg, J., et al. (2005) Occupational Dermal Exposure to Permanent Hair Dyes among Hairdressers. Annals of Occupational Hygiene, 49, 473-480. http://dx.doi.org/10.1093/annhyg/mei030

[23] Chen, S.C., Chen, C.H., Tioh, Y.L., Zhong, P.Y., Lin, Y.S. and Chye, S.M. (2010) Paraphenylenediamine Induced DNA Damage and Apoptosis through Oxidative Stress and Enhanced Caspase-8 and -9 Activities in Mardin-Darby Canine Kidney Cells. Toxicology in Vitro, 24, 1197-1202. http://dx.doi.org/10.1016/j.tiv.2010.02.011

[24] Hueber-Becker, F., Nohynek, G.J., Dufour, E.K., Meuling, W.J.A., de Bie, A.T.H.J., Toutain, H. and Bolt, H.M. (2007) Occupational Exposure of Hairdressers to a [14C]-Para-phenylenediamine-containing Oxidative Hair Dyes: A Mass Balance Study. Food and Chemical Toxicology, 45, 160-169. http://dx.doi.org/10.1016/j.fct.2006.08.002

[25] Cho, J.A., Oh, E., Lee, E. and Sul, D. (2003) Effects of Hair Dyeing on DNA Damage in Human Lymphocytes. Journal of Occupational Health, 45, 367-381. http://dx.doi.org/10.1539/joh.45.376

[26] Sardas, S., Aygun, N. and Karakaya, A.E. (1997) Genotoxicity Studies on Professional Hair Colorist Exposed to Oxidation Hair Dyes. Mutation Research, 394, 153-161. http://dx.doi.org/10.1016/S1383-5718(97)00135-6

[27] Cogliano, V.J., Grosse, Y., Baan, R.A., et al. (2005) Meeting Report: Summary of IARC Monographs on Formaldehyde, 2-Butoxyethanol, and 1-Tert-butoxy-2-propanol. Environmental Health Perspectives, 113, 1205-1208. http://dx.doi.org/10.1289/ehp.7542

[28] Lee, A. and Nixon, R. (2001) Occupational Skin Disease in Hairdressers. Australasian Journal of Dermatology, 42, 16. http://dx.doi.org/10.1046/j.1440-0960.2001.0463b.x 